\title{
What are the maternal risks and pregnancy outcomes after kidney transplantation?
}

\author{
Amera Bekhatro Awad Allah Rashed ${ }^{* 1}$, Mohamed Magdy Sharaf ${ }^{2}$ \\ ${ }^{1}$ Maternal and Newborn Health Nursing Department, Faculty of Nursing, Menoufia University, Egypt \\ ${ }^{2}$ Nephrology, Wadi Elnil Hospital, Egypt
}

Received: July 29, 2018

DOI: $10.5430 / \mathrm{cns} . v 6 \mathrm{n} 4 \mathrm{p} 111$
Accepted: September 16, $2018 \quad$ Online Published: September 25, 2018

URL: https://doi.org/10.5430/cns.v6n4p111

\begin{abstract}
Background: Pregnancy after kidney transplantation should be considered as a major concern. Women with transplanted kidney were able to conceive for more than 50 years. Little studies are available highlighting the effects of transplantation on fetal and neonatal health.

Purpose: This study was conducted with the purpose of identifying the maternal risks and pregnancy outcomes after kidney transplantation.

Methods: Research design: A descriptive (non-experimental) design was used in conducting this study. Tools: Three tools were used during the course of this study, the interviewing questionnaire sheet, maternal risks assessment sheet and pregnancy outcomes sheet.

Results: Regarding the maternal risks, there was a significant increase in mean serum creatinine, decrease in estimated glomerular filtration rate, increase in proteinuria, reported abortion rate was $16.3 \%$, pregnancy induced hypertension rate was $20.9 \%$; Among acquired infections, primary herpes simplex was very common with a rate of $18.6 \%$ while urinary tract infection rate was $39.5 \%$. Among pregnancy outcomes, the mean gestational age was $35.4 \pm 3$, mean birth weight was $2,107.8 \pm 567.7$ and $74.4 \%$ of women delivered by C.s. $30.2 \%$ of delivered infants experienced incubator admission.

Conclusions: The current findings succeeded in answering both study questions.

Recommendation: Pregnant women with kidney transplantation should be followed-up more frequent than normal women for early detection of any risks and for obtaining favorable pregnancy outcomes. Women should be monitored frequently for kidney functions, early signs of pregnancy induced hypertension, acquired infections and other maternal risks reported by this study.
\end{abstract}

Key Words: Maternal risks, Pregnancy, Kidney transplantation

\section{INTRODUCTION}

Kidney transplantation is considered a major novel of modern medicine that provides new life to patients with renal failure especially those with end-stage renal disease (ESRD). The procedure which was experimental, very dangerous, very limited treatment option 50 years ago is considered now a routine clinical process in more than 80 countries around the world. The procedure was limited to individuals in leading academic centers in high-income economies is now transforming lives as a routine procedure in most middle-income countries. ${ }^{[1]}$

The year 1976 was a highlighted landmark for renal transplantation in Egypt: the first operation was performed in Mansoura. ${ }^{[2]}$ After a very slow start, the number of such

\footnotetext{
*Correspondence: Amera Bekhatro Awad Allah Rashed; Email: amera.rashed@yahoo.com; Address: Maternal and Newborn Health Nursing Department, Faculty of Nursing, Menoufia University, Egypt.
} 
operation gradually increased, reaching an annual rate of 90-100 cases of transplants. Nowadays, there are 80 centers that perform renal transplantation in Egypt, with a number exceeding 7,000 living donors. ${ }^{[3]}$

Pregnancy is uncommon in women with ESRD on chronic dialysis. ${ }^{[4]}$ With progressive renal disease; sexual interest and fertility decrease. ${ }^{[5]}$ However, women with renal transplantation may have favorable pregnancy and live birth rates. From the physiological aspect, function of the hypothalamus ${ }^{[6]}$ and ovulatory functions ${ }^{[7]}$ in women with end stage renal disease become normal mostly after the operation. Low percent $(2 \%)$ of women with kidney transplantation at reproductive age conceive at the follow-up phase. ${ }^{[6,8]}$ Although the useful effects of kidney transplantation, such women are among the high-risk group during pregnancy, with a serious feto-maternal problems. ${ }^{[6,8]}$

Women with renal transplantation need to evaluate potential neonatal outcomes, graft outcomes, and risks to their own health to carefully make informed decisions about conception. Pregnancy should be carefully planned in such women to reduce risks for graft loss, optimize pregnancy outcomes, and ensure a nonteratogenic immunosuppression regime.

The optimal timing of pregnancy after renal transplantation depends on woman condition. Historically, the recommendation for pregnancy timming was to wait for two years after the operation. ${ }^{[8]}$ Now such recommendation has been replaced by the "American Society of Transplantation Consensus Opinion": (1) a wait period of minimum one year for those received the organ from a living related donor and two years for a living not-related donor; (2) serum creatinine $(<2 \mathrm{mg} / \mathrm{dl})$, without recent case of acute rejection or signs of ongoing rejection; (3) absence of or minimal proteinuria (<0.5 g/d); (4) normal kidney ultrasound findings; and (5) low dose of immunosuppressive drugs and withdrawal of mycophenolate mofetil and sirolimus. ${ }^{[9-13]}$

Pregnancy can disturb different kidney functions. Kidney and systemic hemodynamics changes are in the form of significant volume expansion and vasodilation. Compared to the nonpregnant condition; glomerular filtration rate increases $50 \%$ and renal plasma flow increases up to $80 \% .{ }^{[13]}$ Tubular function and handling of water and electrolytes are altered, leading to mild increases in proteinuria, glucosuria, lower serum osmolality, and reductions in serum sodium levels. The kidneys are larger during pregnancy because of fluid retention, and physiologic hydronephrosis is very common. The aforementioned changes represent a load for the suboptimal allograft function and this issue increase fetal and maternal risks for complications.
Pregnancy in renal transplant recipients is considered "high risk" because pregnant woman and offspring may experience complications related to previous underlying diseases and suboptimal allograft function. Women with transplantation adhere to a life long course of immunosuppressive agents and blood thinners which may pose a risk during pregnancy. Proposed potential maternal complications include hypertension or preeclampsia, deterioration of graft function and urinary tract infections. The unborn child is susceptible to drug toxicity and congenital infections.

First MR et al. ${ }^{[15]}$ reported in a previous study that the gestational rate was $3.3 \%$ in the USA during the 1 st three years after the operation. Different studies reported favorable pregnancy outcomes. ${ }^{[16-18]}$ In a detailed meta-analysis, Pergola PE et al. ${ }^{[19]}$ reported the live birth rate and abortion rates to be $73.5 \%$ and $14.0 \%$, respectively after transplantation. However, women with transplantation are liable to high risk for feto-maternal complications, like gestational hypertension, diabetes, preterm labor, and small for gestational age. ${ }^{[8]}$ Women with a prepregnancy creatinine $>1.7 \mathrm{mg} / \mathrm{dl}$ are more likely to experience deteriorated kidney function and a rise in creatinine level after pregnancy than women with better prepregnancy kidney function.

Neonatal outcomes remain significantly worse for such women than healthy ones, especially for those with reduced graft function, so that antenatal and postpartum care of women with renal transplantation should be guided by a multidisciplinary team of nephrologists and specialist obstetricians. ${ }^{[9]}$ In a report from the National Transplantation Pregnancy Registry (NTPR): outcomes of pregnancy after transplantation; prematurely and small for age were the most reported complications, affecting about $50 \%$ of newborns. Fortunately, feto-maternal outcomes are likely to be favorable during the following pregnancies. ${ }^{[20-23]}$

\subsection{Significance of the study}

Becoming pregnant is a very important and emotive topic for all women of childbearing age underwent kidney transplantation. There are some valuable, patient-centered sources of information about pregnancy after transplantation and its possible risks and complications. ${ }^{[22]}$ However, there is also much misleading information, which is not evidence-based or old-fashioned. Therefore, it is vital for obstetricians to remain aware of developments in the field and to actively counsel women about pregnancy complications and risks after transplantation.

The available body of knowledge on pregnancies among kidney transplant recipients is based on case reports, few reviews, ${ }^{[4,5]}$ single-center studies and four voluntary reg- 
istries: ${ }^{[23,24]}$ [A] National Transplantation Pregnancy Registry (NTPR) in the US [B], European Dialysis and Transplant Association Registry [C], the UK Transplant Pregnancy Registry and the Australia and New Zealand Dialysis and Transplant Registry (ANZ-DATA) [D]. In the most recent meta-analysis from 2011, 4,706 pregnancy cases among 3,570 case of kidney transplantation were reported from 2000 till $2010^{[25]}$ without clearly reported data about either maternal risks or pregnancy outcomes.

Few studies have been published in Egypt and very limited data are available regarding the risks and outcomes of pregnancy among such women. This study is considered an analytical description of a number of pregnancies among women with stable kidney transplantation condition. It tries to point out the potential maternal risks and pregnancy outcomes as a step toward future formulation of adequate plan of care for pregnant women and fetus.

\subsection{Purpose of the study}

This study was conducted with the purpose of identifying the maternal risks and pregnancy outcomes after kidney transplantation.

\subsection{Research questions}

- What are the maternal risks during pregnancy after kidney transplantation?

- What are pregnancy outcomes after kidney transplantation?

\section{MeTHODS}

\subsection{Research design}

A descriptive (non-experimental) design was used in conducting this study. ${ }^{[26]}$

\subsection{Setting}

Data were primarily collected from the follow-up clinic in the following settings: Wadi Elnil hospital (Armed forces hospital), kidney hospital and liver transplantation (Maadi Medical Complex of the Armed Forces), specialized air hospital. Those settings were selected due to: the availability of cases and the very accurate follow-up and archiving system (Electronic Medical Record system).

\subsection{Subjects}

Women who met the study inclusion criteria were purposively selected from the follow-up clinics at the aforementioned settings and recruited in the study. The inclusion criteria were the International Classification of Diseases codes of "V22: normal pregnancy" and "V42.0 kidney replaced by transplant" in addition to: stable kidney condition and agreement to participate in the study.

Published by Sciedu Press
The sample size and sampling procedure:

The researchers recruited the whole study population as a study sample (all eligible women according to the inclusion criteria) as the population was limited in size (only 43 women).

The sample was distributed as follows:

Wadi Elnil hospital: 10 women, kidney hospital and liver transplantation: 12, specialized air hospital 21.

\subsection{The filed work}

The data collection was conducted from March 2015 to February 2018.

Maneuver of Intervention: The following steps were done consecutively.

Step I: An extensive reviewing of electronic data related to effects of kidney transplantation on fertility and pregnancy after transplantation was done. A review of literature to collect relevant knowledge pertinent to study was also used in developing data collection instruments.

Step II: The field work was scheduled in the form of one visit to the follow-up clinic at each study setting per week. The researchers recruited women coming for their regular kidney status follow-up while they are at the first trimester of pregnancy.

Step III: After agreement to participate in the study, the researchers explained the purpose of the study, obtained an oral informed consent, sit schedule for follow-up times, identified methods of contacting with women and then used instrument I (interviewing questionnaire sheet) to record basic data.

Step IV: The researchers followed up women along the course of pregnancy until delivery using instrument II (maternal risks assessment sheet). At delivery, the researchers tried to attend the procedure to record data using instrument III (pregnancy outcomes sheet). For some cases (9 cases), the researchers recorded needed data from the obstetrician and the pediatrician attended the delivery procedure.

\subsection{Data collection instruments}

Three instruments were used during the course of this study: (I) interviewing questionnaire sheet, (II) maternal risks assessment sheet and (III) pregnancy outcomes sheet.

I: The interviewing questionnaire sheet was developed by the researchers and submitted to validity and reliability tests. It included: (1) Basic data of studied women, age, duration of marriage, education, occupation, residence and income. (2) Obstetric history/data about current pregnancy. (3) Data about kidney disease (obtained from the electronic medical 
record system). (4) Data about transplantation procedure/ timing, duration between transplantation and pregnancy, follow up doses of immunosuppressant drugs, blood thinners and follow-up schedule.

Validity of the interviewing questionnaire was ascertained by a group of subject areas experts, medical and nursing staff who reviewed the instrument for content validity. They were asked also to judge the items for completeness and clarity. Suggestions were incorporated into the instrument. Testretest reliability was applied by the researchers for testing the internal consistency of the interviewing questionnaire. It is the administration of the same instrument to the same participant under similar conditions on two or more occasions. Scores from repeated testing were compared.

II: Maternal risks assessment sheet. It was developed by the researchers and submitted to validity and reliability tests. It included: pregnancy induced hypertension, gestational diabetes, graft loss, kidney functions (from follow-up medical record) and any other recorded risks. Validity of instrument II was ascertained by a group of subject areas experts, medical and nursing staff who reviewed the instrument for content validity. They were asked also to judge the items for completeness and clarity. Suggestions were incorporated into the instrument.

Test-retest reliability was applied by the researchers for testing the internal consistency of the interviewing questionnaire. It is the administration of the same instrument to the same participant under similar conditions on two or more occasions. Scores from repeated testing were compared.

III: Pregnancy outcomes sheet. It was developed by the researchers and submitted to validity and reliability tests. It included: age of gestation, neonatal birth weight, and Apgar scores at the 1st minute and 5th minute after birth. Neonatal complications such as: birth injuries, small for gestational age and prematurity.

Validity of instrument III was ascertained by a group of subject areas experts, medical and nursing staff who reviewed the instrument for content validity. They were asked also to judge the items for completeness and clarity. Suggestions were incorporated into the instrument. Test-retest reliability was applied by the researchers for testing the internal consistency of the interviewing questionnaire. It is the administration of the same instrument to the same participant under similar conditions on two or more occasions. Scores from repeated testing were compared.

\subsection{Administrative design}

Official steps were taken to obtain a permission to conduct the study. An official agreement was granted first from fac- ulty of nursing authority. The protocol for the research was approved by the ethical and hearing jury of faculty of nursing. Then permissons from the aforementioned hospitals' authorities after explanation of the aim and the importance of the study was granted.

\subsection{Ethical consideration}

After explanations prior to enrollment in the study, an informed written consent was obtained from all women before participation in the study. Each participant was informed that participation was voluntary, and she could withdraw from the study whenever she decided to and each one was given the opportunity to freely refuse participation. They were free to ask any question about the study details. Women were assured that their information were confidential and only used for study process also the finding would be presented as a group data with no personal participant's information remained.

\subsection{Piloting the instruments}

A Piloting was conducted on five women (10\% of the total sample) to test the applicability of the tools and to estimate the time needed for data collection. On the basis of the piloting results the researchers determined the feasibility of data collection procedures, developed an interview schedule. The results of the piloting help in refining the interview questionnaire. The sample of the pilot study was not excluded from the main study sample as the population was limited in size.

\subsection{Statistical data analysis}

The current collected data were tabulated and then analyzed using statistical package for the social science (SPSS) software version 20 on IBM compatible computer. Quantitative data were expressed as mean \& standard deviation $(\bar{x} \pm S D)$.

\section{RESULTS}

Table 1 shows the sociodemographic characteristics of the studied women. It shows that the majority of them was highly educated, urban residents, and was living away from their husbands' family.

The maternal transplantation related data are summarized in Table 2. The mean age of women at transplantation was $24 \pm 8$ years. The mean age at the time of pregnancy was $28 \pm 6$ years. $34.9 \%$ of women had transplantation due to rapidly progressive glomerulonephritis and the same percentage due to systemic lupus erythematosus. The mean duration from transplantation to current pregnancy was 7 years and 2 months with a standard deviation of 4 years and 1 month. 
Table 1. Sociodemographic data

\begin{tabular}{lll}
\hline Variable & No (43) & \% \\
\hline $\begin{array}{l}\text { Level of education } \\
\text { - Secondary }\end{array}$ & 4 & 9.4 \\
- University & 39 & 90.6 \\
Residence & & \\
- Urban & 37 & 86 \\
- Rural & 6 & 14 \\
Accommodation & & \\
- With husband family & 38 & 88.3 \\
- With husband alone & 5 & 11.7 \\
Monthly income & & \\
- Enough & & 58.2 \\
- Not-enough & 25 & 41.8 \\
\hline
\end{tabular}

Table 3 displays the immunosuppressant treatment protocols before and during pregnancy. The table shows that nearly half of women were using steroid, mycophenolate mofetil and cyclosporine before pregnancy. During pregnancy, mycophenolate mofetil was prohibited and the majority of women were using only Steroid and azathioprine. All women were using low dose aspirin before and during pregnancy.

There was a significant increase in mean serum creatinine from baseline to the third trimester of pregnancy, and this negative effect was maintained at follow-up, as shown in Table $4(1.18 \pm 0.06 \mathrm{mg} / \mathrm{dl}$ at baseline, vs. $1.46 \pm 0.14$ $\mathrm{mg} / \mathrm{dl}$ at $3 \mathrm{rd}$ trimester, vs. $1.58 \pm 0.21 \mathrm{mg} / \mathrm{dl}$ at follow-up, $p<.001)$. There was a decrease in estimated glomerular filtration rate (eGFR) and an increase in proteinuria $(0.09 \pm$ $0.1 \mathrm{~g} / \mathrm{L}$ at baseline, vs. $0.20 \pm 0.09 \mathrm{~g} / \mathrm{L}$ at 3 rd trimester, vs. $0.29 \pm 0.07 \mathrm{~g} / \mathrm{L}$ at follow-up, $p<.001)$.

Table 2. Maternal transplantation related data

\begin{tabular}{lll}
\hline Variable & No (43) & $\%$ \\
\hline Cause of end-stage renal disease & & \\
- Chronic glomerulonephritis & 13 & 30.2 \\
- Rapidly progressive glomerulonephritis & 15 & 34.9 \\
- Systemic lupus erythematosus & 15 & 34.9 \\
Mean age at transplantation, years & $24 \pm 8$ & \\
- $<20$ years & 14 & \\
- 20-31 years & 22 & \\
- $\geq 32$ years & 7 \\
Mean age at pregnancy, years & $28 \pm 6$ & \\
- $<20$ years & 0 & \\
- 20-34 years & 32 \\
- $\geq 35$ years & 11 & \\
Duration from transplantation to current pregnancy & $7 \mathrm{y} 2 \mathrm{~m} \pm 4$ y $1 \mathrm{~m}$ & \\
\hline
\end{tabular}

Table 3. Immunosuppressive and blood thinners protocols before and during pregnancy

\begin{tabular}{lll}
\hline Variable & No (43) & $\%$ \\
\hline Treatment protocol before pregnancy & & \\
- Steroid and azathioprine & 5 & 11.63 \\
- Steroid, azathioprine and cyclosporine & 17 & 39.53 \\
- Steroid, mycophenolate mofetil and cyclosporine & 21 & 48.83 \\
Low dose aspirin & 43 & 100 \\
- Treatment protocol during pregnancy & & \\
- Steroid and azathioprine & 28 & 65.12 \\
- Steroid, azathioprine and cyclosporine & 15 & 34.88 \\
- Low dose aspirin & 43 & 100 \\
\hline
\end{tabular}


Table 4. Renal function and proteinuria among pregnant woman, at baseline, during pregnancy and during follow-up visit

\begin{tabular}{lllllll}
\hline Variable & Baseline & 1 Trimester & 2 Trimester & 3 Trimester & Follow-up & $\boldsymbol{p}$ \\
\hline Serum Creatinine, $\mathrm{mg} / \mathrm{dl}$ & $1.18 \pm 0.06$ & $1.07 \pm 0.06$ & $1.16 \pm 0.11$ & $1.46 \pm 0.14$ & $1.58 \pm 0.21$ & $<.001$ \\
Estimated GFR, $\mathrm{ml} / \mathrm{min} / 1.73 \mathrm{~m}^{2}$ & $72.24 \pm 26.76$ & $81.11 \pm 27.02$ & $80.99 \pm 34.65$ & $60.76 \pm 23.43$ & $62.05 \pm 25.91<.001$ \\
Proteinuria, g/L & $0.09 \pm 0.1$ & $0.13 \pm 0.02$ & $0.19 \pm 0.04$ & $0.20 \pm 0.09$ & $0.29 \pm 0.07$ & $<.001$ \\
\hline
\end{tabular}

Note. GFR: Glomerular filtration rate, estimated by CKD-EPI equation

Table 5. Maternal risks

\begin{tabular}{lll}
\hline Variable & No (43) & \% \\
\hline Abortion & & \\
- $1^{\text {st }}$ trimester & 7 & 16.3 \\
- Pregnancy induced hypertension & 9 & 20.9 \\
- Gestational diabetes & 2 & 4.6 \\
Acquired infections & & \\
- Cytomegalovirus & 2 & 4.6 \\
- Toxoplasmosis & 6 & 13.9 \\
- Primary herpes simplex & 8 & 18.6 \\
- Primary varicella & 5 & 11.6 \\
Other recorded maternal risks & & \\
- Graft loss & 2 & 4.6 \\
- Urinary tract infection & 17 & 39.5 \\
\hline
\end{tabular}

Table 6. Pregnancy outcomes

\begin{tabular}{lll}
\hline Variable & No (43) & \% \\
\hline Gestational age (by weeks) & $35.4 \pm 3$ & \\
- Preterm (<34 wk) & 5 & 11.6 \\
Birth weight (by grams) & $2,107.8 \pm 567.7$ & \\
Apgar score (1 st minute) $^{\text {th }}$ minute) & Mean: 6.5 & \\
Apgar score (5 & Mean: 7.5 & \\
Mode of delivery & & \\
- Normal & 11 & 25.6 \\
- C.S. & 32 & 74.4 \\
Reason for section & & \\
- Cephalo-pelvic disproportion & 4 & 12.5 \\
- Fetal distress & 1 & 2.3 \\
- Previous C/S & 4 & 12.5 \\
- Severe preeclampsia & 2 & 4.6 \\
- Induction failure & 3 & 9.3 \\
- Woman's preference & 18 & 41.9 \\
Congenital anomalies & 3 & 9.3 \\
NICU admission & 4 & 12.5 \\
Incubator admission & 13 & 30.2 \\
Intrauterine fetal death & 2 & 4.6 \\
\hline
\end{tabular}

The maternal risks during pregnancy are displayed in Table 5 . The table shows that urinary tract infection was the most reported complication. Only two experienced graft loss. Seven 116 women experienced first trimester abortion. Pregnancy induced hypertension and diabetes were reported by 9 and 2 women consecutively. The reported infection types were variable due to the immunosuppressants use, the highest incidence recorded was primary herpes simplex.

Tables 4 and 5 answered the first research question: Which was "What are the maternal risks during pregnancy after kidney transplantation?"

Pregnancy outcomes are showed in Table 6. The table shows that the mean gestational age was $35.4 \pm 3$. The mean birth weight was 2,107.8 \pm 567.7 grams. The mean Apgar score at 1 minute was 6.5 and after 10 minutes was 7.5. Thirty two women delivered by C.S due to previous section and severe preeclampsia. Congenital anomalies were reported in three newborn babies. Only two cases experienced intrauterine fetal death.

Table 6 answered the second research question: Which was "What are the pregnancy outcomes after kidney transplantation?"

\section{Discussion}

The idea of organ and parts transplantation attracted the attention of ancient Egyptians. The Great Sphinx is a symbol of a human head transplanted into a body of lion. The Egyptians never stop dreaming until the transplantation practice became a reality. March 1976, the first renal transplantation in Egypt was carried out in Mansoura. October 1976 in Cairo University: the first renal transplantation was performed in Kasr El-Aini Hospital. ${ }^{[27]}$ After that the practice spread allover Egypt.

This study is considered an analytical description of a number of pregnancies among women with stable kidney transplantation condition. Although the studied women experienced pregnancy occurred in a non-late age and mostly after relatively few years post transplantation, the number of abortion was higher compared to the Egyptian general population $(15 \%)^{[28]}$ and also higher compared to the general abortion rate reported around the world (12\% to $15 \%) .{ }^{[29,30]}$

As for the maternal transplantation related data, women experienced ESRD as a result of many conditions like chronic 
glomerulonephritis, rapidly progressive glomerulonephritis and systemic lupus erythematosus. In 2016, Sturgiss SN et al. ${ }^{[16]}$ conducted a study about effects of pregnancy on the mother with transplantation and her child, and pointed out similar causes of ESRD.

The mean age of studied women at transplantation was $24 \pm 8$ and at conception was $28 \pm 6$ which is considered the mid-fertility, non-late age compared to the general population. Similar age of transplantation and conception was reported by Kim HW et al. ${ }^{[8]}$ in a study of pregnancy following renal transplantation.

In the current study, the studied women became pregnant after a mean of 7 years $( \pm 4 \mathrm{y})$ from transplantation. On contrast, the current recommendations for pregnancy after kidney transplantation by "American Society of Transplantation Consensus Opinion" included a waiting a wait period of minimum one year for those received the organ from a living related donor and two years for a living not-related donor. ${ }^{[31]}$

Regarding immunosuppressive treatment protocols before and during pregnancy, the majority of studied women were using steroid, mycophenolate mofetil and cyclosporine before pregnancy and then switched to only steroid and azathioprine during pregnancy because gestational use of mofetil was reported to be linked to malformations and first trimester abortion. ${ }^{[32]}$ A recent review by Polit FD et al. ${ }^{[25]}$ described the use of immunosuppressants during the previous 30 years. Before 1990, most pregnant women used a combination of azathioprine and prednisone, and at the period from 1991 to 2000 , women used cyclosporine. Since $2001,54 \%$ of women used cyclosporine and $35 \%$ of women have used tacrolimus. On the same line, Armenti VT et al. ${ }^{[33]}$ also added that mofetil was FDA pregnancy category D in 2008. The use of blood thinners is considered a life-long treatment and used by all kidney recipients.

As for the increase in creatinine and decrease in eGFR along pregnancy and at follow-up visits after delivery; in the available published data, pregnancy did not appear to massively affect kidney conditions in stable transplant women. ${ }^{[34]}$ The demographic characteristics of the current studied women may be different. The immunosuppression regimen and the number of visits during pregnancy were different compared to several studies contributing to the different results. The effect of this worsening in renal function of the studied women on graft condition is a vital issue for future researches.

Regarding abortion, seven women experienced 1st trimester pregnancy loss. On contrast, among women with kidney transplantation, studies reported that approximately $35 \%$ of pregnancies do not progress beyond the 1st trimester due to spontaneous or therapeutic abortion and that overall success rate is $>90 \%$ after the 1 st trimester. ${ }^{[34]}$ The contradiction in results may be due to stopping of mycophenolate in the current sample which has influenced the current results. Moreover some of the studies included in the aforementioned systemic review were before FDA categorization of Mycophenolate mofetil as pregnancy category D so it was increasing the incidence of abortion.

Regarding pregnancy induced hypertension; its reported rate was $20.9 \%$. Hypertension in general is common among women suffering from chronic renal diseases, still present after transplantation, and become worse during pregnancy among women on immunosuppressants. ${ }^{[35]}$ A recent study published similar rate of hypertension during pregnancy with similar rationale.

As for gestational diabetes rate in the current study, it was $4.6 \% .{ }^{[36]}$ Conducted a study about management of pregnancy after kidney transplantation and recorded a rate of $6 \% .{ }^{[36]}$ Also reported that women with transplantation have increased incidence for developing diabetes, and they should be checked periodically during pregnancy using glucose tolerance test.

Recorded maternal acquired infections were cytomegalovirus, toxoplasmosis, primary herpes simplex and primary varicella with the highest incidence of herpes simplex. Women with transplantation are liable to different types of infection due to long term use of immunosuppressive; so, infection transmission needs to be beared in mind as a potential risk for the mother and the fetus. ${ }^{[37-40]}$ reported in different studies that infection with cytomegalovirus can be dangerous as it is linked to senses loss and sometimes mental retardation and can pass the placental barriers, and during the course of labor and even breastfeeding. HIV and hepatitis $\mathrm{B}$ or $\mathrm{C}$ are amongst other types of infections that the women may be threatened. ${ }^{[38,39]}$

One of the most common reported complications after kidney transplantation is the urinary tract infection, its incidence was $39.5 \%$ in the current study. This rate of infection was observed although there was a continuous prophylaxis with antimicrobial agent. The reported rate is rationalized by the use of immunosuppressants plus the normal adaptive changes in the urinary tract during pregnancy. ${ }^{[41]}$ In a study about conception among kidney transplantation women reported high incidence of urinary tract infection of their studied women.

Graft loss means the need for permanent dialysis or retransplantation. It was reported by only two women this is considered a low rate in relation to the total sample number. The loss was caused by the increased kidney workload 
imposed by pregnancy. ${ }^{[42]}$ Reported similar outcome by publishing that "pregnancy in women with a functioning graft does not have an adverse impact on long-term graft survival".

The pregnancy outcomes described in the current study were: age of gestation, type of delivery, Apgar score, neonatal weight, congenital anomalies, NICU admission, incubator admission and intrauterine fetal death. As for the gestational age; the recorded mean was $35.4 \pm 3$ weeks. The reported mean was similar to the most recent rate based on data from the Australia and New Zealand Dialysis and Transplant Registry which was 35.4 weeks. However, it is considered slightly more than that reported by Coscia LA $(34.3 \pm 3) .^{[18]}$

The preterm delivery rate was $11.6 \%$, and it is lower than the rate of $24.8 \% .^{[18]}$ The difference in rate is seen to be due to large sample size studied by Coscia LA ${ }^{[18]}$ and the previous history of preterm delivery among the sample.

The mean birth body weight in the current study was 2,107.8 $\mathrm{g}$ which is little than that reported by Polit FD et al. $(2,485 \mathrm{~g}) .{ }^{[25]}$ The difference in weight may be due to the different eating habits and the activities of daily living of sample.

The mean Apgar score at one and five minutes was satisfying and similar to means of multiple studies ${ }^{[43]}$ both reported favorable and satisfying means.

One of the commonest obstetric complications observed in the current study was cesarean section, reported at a rate of $74.4 \%$. It is surprising that high incidence of neonates was born through C.s. however the transplanted kidney is outside the true pelvis and doesn't necessitate the need for C.s. Obstetrician opinion is that if there is an obstetric indication to C.s., vaginal delivery is allowed and even preferred ${ }^{[44]}$ But the Egyptian concept of "Golden baby" is judging the choice between vaginal and C.S. The current rate was more than the rate reported by Coscia $\mathrm{LA}^{[18]}$ due to cultural factors.

Fortunately, only three infants were delivered suffering from congenital anomalies. Reported anomalies were suspected to be effect of in utero exposure to immunosuppressants on organogenesis and maturation. ${ }^{[45]}$ Studied "pregnancy in kidney transplanted patients: a review of outcomes, complications, and management" and reported limited number of congenital anomalies and rationalized by mycophenolate mofetil use.

Immunosuppressive effects on the fetus are expressed by the occurrence of malformations seen clearly at birth. Published data indicate that the incidence of congenital malformations is not higher than that in the general population. In utero exposure to MMF has been studied, as it may be linked to major congenital anomalies. ${ }^{[46-48]}$ Data about different types of medications is insufficient till now. It is clearly noticed that it can be difficult to determine the type of medication responsible for malformation as women are using a combination of such types of medication.

The reported rates of NICU admission, incubator admission and intrauterine fetal death were relatively low compared to available body of knowledge, that point to high risk for NICU admission, incubator admission and intrauterine fetal death.

The incidence of these parameters was between $12 \%$ and $17 \%$ among women with kidney transplantation, this can be due to the experienced high blood pressure, renal disease and the liability of such women to develop have preeclampsia. ${ }^{[36,42,44,49]}$ On contrast, the current studied women were with stable kidney condition.

\section{Conclusions}

The current findings succeeded in answering both study questions. Question 1: What are the maternal risks during pregnancy after kidney transplantation? Regarding the maternal risks; there was a significant increase in mean serum creatinine, decrease in estimated glomerular filtration rate, increase in proteinuria, reported abortion rate was $16.3 \%$, pregnancy induced hypertension rate was $20.9 \%$, among acquired infections; primary herpes simplex was very common with a rate of $18.6 \%$ while urinary tract infection rate was $39.5 \%$. Question 2: What are pregnancy outcomes after kidney transplantation? Among pregnancy outcomes; the mean gestational age was $35.4 \pm 3$, mean birth weight was $2,107.8$ \pm 567.7 and $74.4 \%$ of women delivered by C.s. $30.2 \%$ of delivered infants experienced incubator admission.

\section{Recommendations}

Pregnant women with kidney transplantation should be followed-up more frequent than normal women for early detection of any risks and for obtaining favorable pregnancy outcomes.

Women should be monitored frequently for kidney functions, early signs of pregnancy induced hypertension, acquired infections and other maternal risks reported by this study.

The delivery timing, type, place and attending team should be planned well by the medical team for favorable maternal and neonatal outcomes.

These women are at risks for developing many complications during pregnancy. However, with proper counseling regarding optimal time of pregnancy, these women can have good pregnancy outcomes. 
Pregnancy following kidney transplantation should be managed as a high-risk gestation, and must be followed-up in a multidisciplinary way.

This study highlighted the need for more investigation about pregnancy after kidney transplantation using larger sample and in a quasi-experimental way.

\section{REFERENCES}

[1] Bakr MA. Renal transplantation in Egypt. Organs Tissues. 2000; 1: 39-44.

[2] Barsoum R, Bakr MA. The Egyptian renal transplant experience. Clin Transpl. 2000; 359-360. PMid: 11512334.

[3] Holley JL, Reddy SS. Pregnancy in dialysis patients: a review of outcomes, complications, and management. Semin Dial. 2003; 16: 384-8.

[4] Groothoff J. Pregnancy during dialysis: still a challenge to get there, but worth the effort. Nephrol Dial Transplant. 2015; 30: 1053-5. PMid: 25934990. https://doi.org/10.1093/ndt/gfv124

[5] McKay DB, Josephson MA. Pregnancy in recipients of solid organs effects on mother and child. N Engl J Med. 2016; 354: 1281-93. PMid: 16554530. https://doi.org/10.1056/NEJMra050431

[6] Ha J, Kim SJ, Kim ST. Pregnancy following renal transplantation. Transplant Proc. 1994; 26: 2117-8.

[7] Davison JM, Bailey DJ. Pregnancy following renal transplantation. J Obstet Gynaecol Res. 2013; 29: 227-33. https ://doi.org/10.1 046/j.1341-8076.2003.00106.x

[8] Kim HW, Seok HJ, Kim TH, et al. The experience of pregnancy after renal transplantation: pregnancies even within postoperative 1 year may be tolerable. Transplantation. 2008; 85: 1412-9. PMid: 18497680. https://doi.org/10.1097/TP.0b013e318170f8e d

[9] Mastrobattista JM, Katz AR. Pregnancy after organ transplant. Obstet Gynecol Clin North Am. 2004; 31: 415-28, vii. PMid: 15200970. https://doi.org/10.1016/j.ogc.2004.03.005

[10] Watnick S. Pregnancy and contraceptive counseling of women with chronic kidney disease and kidney transplants. Adv Chronic Kidney Dis. 2007; 14: 126-31. PMid: 17395115. https://doi.org/10.1 053/j.ackd. 2007.01.003

[11] EBPG Expert Group on Renal Transplantation. European best practice guidelines for renal transplantation. Section IV: long-term management of the transplant recipient. IV.10. Pregnancy in renal transplant recipients. Nephrol Dial Transplant. 2002; 17(Suppl. 4): 50-5.

[12] Dunlop W. Serial changes in renal hemodynamics during normal human pregnancy. Br J Obstet Gynaecol. 1981; 88(1): 1-9. PMid: 7459285. https://doi.org/10.1111/j.1471-0528.19 81.tb00929.x

[13] Gill JS, Zalunardo N, Rose C, et al. The pregnancy rate and live birth rate in kidney transplant recipients. Am J Transplant. 2009; 9: 1541-9. PMid: 19459800. https://doi.org/10.1111/j.16 00-6143.2009.02662.x

[14] Del Mar Colon M, Hibbard JU. Obstetric considerations in the management of pregnancy in kidney transplant recipients. Adv Chronic Kidney Dis. 2007; 14: 168-77. PMid: 17395119. https: //doi.org/10.1053/j.ackd.2007.01.007

[15] First MR, Combs CA, Weiskittel P, et al. Lack of effect of pregnancy on renal allograft survival or function. Transplantation. 1995; 59:

\section{ACKNOWLEDGEMENTS}

The authors acknowledge all those who contributed towards the study by making substantial contributions to acquisition of data, analysis and interpretation.

\section{CONFLicts of InTEREST Disclosure}

The authors declare they have no conflicts of interest.
472-6. PMid: 7878748. https://doi.org/10.1097/00007890 $-199502270-00004$

[16] Sturgiss SN, Davison JM. Effect of pregnancy on the long-term function of renal allografts: an update. Am J Kidney Dis. 1995; 26: 54-6. https://doi.org/10.1016/0272-6386(95) 90153-1

[17] Deshpande NA, James NT, Kucirka LM, et al. Pregnancy outcomes in kidney transplant recipients: a systematic review and metaanalysis. Am J Transplant. 2011; 11: 2388-404. PMid: 21794084 https://doi.org/10.1111/j.1600-6143.2011.03656.x

[18] Coscia LA, Constantinescu S, Moritz MJ, et al. Report from the National Transplantation Pregnancy Registry (NTPR): outcomes of pregnancy after transplantation. Clin Transpl. 2009; 103-22. PMid: 20524279.

[19] Pergola PE, Kancharla A, Riley DJ. Kidney transplantation during the first trimester of pregnancy: immunosuppression with mycophenolate mofetil, tacrolimus, and prednisone. Transplantation. 2000; 71: 994-997. https://doi.org/10.1097/00007890-2001041 50-00028

[20] LeRay C, Coulomb A, Elefant E, et al. Mycophenolate mofetil in pregnancy after renal transplantation: A case of major fetal malformations. Obstet Gynecol. 2004; 103: 1091-1094. PMid: 15121619. https://doi.org/10.1097/01.AOG.0000124986.32858.ba

[21] Sifontis NM, Coscia LA, Constantinescu S, et al. Pregnancy outcomes in solid organ transplant recipients with exposure to mycophenolate mofetil or sirolimus. Transplantation. 2006; 82: 16981702. PMid: 17198262. https://doi.org/10.1097/01.tp.00 00252683.74584 .29

[22] Armenti VT, Radomski JS, Moritz MJ, et al. Report from the National Transplantation Pregnancy Registry (NTPR): outcomes of pregnancy after transplantation. Clin Transpl. 2000; 123-134. PMid: 11512306.

[23] EBPG Expert Group on Renal Transplantation. European best practice guidelines for renal transplantation. Section IV: long-term management of the transplant recipient. IV.10. Pregnancy in renal transplant recipients. Nephrol Dial Transplant. 2002; 17(Suppl. 4): 50-5.

[24] Wyld ML, Clayton PA, Jesudason S, et al. Pregnancy outcomes for kidney transplant recipients. Am J Transplant. 2013; 13: 3173-82. PMid: 24266970. https://doi.org/10.1111/ajt.12452

[25] Polit FD, Beck CT. Essential of nursing research and methods, Research design. 7th ed. New York: Lippincott William \& Wilkins; 2007. 39-42, 165-230 p.

[26] Barsoum R, Bakr MA. The Egyptian renal transplant experience. Clin Transpl. 2014; 359-360.

[27] Bakr M, Refaie A, Hassan N, et al. Rescue therapy with tacrolimus and MMF after live-donor kidney transplantation. Afr J Nephrol. 2015.

[28] Cecatti JG, Guerra GVQL, Sousa MH, et al. Aborto no Brasil: um enfoque demográfico. Rev Bras Ginecol Obstet. 2013; 32: 105-11. https://doi.org/10.1590/S0100-72032010000300002 
[29] Regan L, Rai R. Epidemiology and the medical causes of miscarriage. Baillières Best Pract Res Clin Obstet Gynaecol. 2014; 14 839-54. PMid: 11023804. https://doi.org/10.1053/beog.2 000.0123

[30] McKay D, Josephson M. Reproduction and transplantation: Report on the AST consensus conference on reproductive issues and transplantation. Am J Transplant. 2015; 5: 1-8.

[31] Pisoni CN, D'Cruz DP. The safety of mycophenolate mofetil in pregnancy. Expert Opin Drug Saf. 2013; 7: 219-22. PMid: 18462179 https://doi.org/10.1517/14740338.7.3.219

[32] Jones A, Clary MJ, McDermott E, et al. Outcomes of pregnancies fathered by solid-organ transplant recipients exposed to mycophenolic acid products. Prog Transplant. 2013; 23: 153-7. PMid: 23782663. https://doi.org/10.7182/pit2013636

[33] Armenti VT, Radomski JS, Moritz MJ, et al. A systematic review: outcomes of pregnancy after transplantation. Clin Transpl. 2016; 123-34.

[34] Cristelli MP, Tedesco-Silva H, Medina-Pestana JO, et al. Safety profile comparing azathioprine and mycophenolate in kidney transplant recipients receiving tacrolimus and corticosteroids. Transpl Infect Dis. 2013; 15: 369-78. PMid: 23701592. https ://doi.org/10.1 111/tid. 12095

[35] Del Mar Colon M, Hibbard JU. Obstetric considerations in the management of pregnancy in kidney transplant recipients. Adv Chronic Kidney Dis. 2012; 14: 168-177. PMid: 17395119. https: //doi.org/10.1053/j.ackd.2007.01.007

[36] Michaels MG. Treatment of congenital cytomegalovirus: Where are we now? Expert Rev Anti Infect Ther. 2010; 5: 441-448. PMid: 17547508. https://doi.org/10.1586/14787210.5.3.441

[37] Gardella C, Brown ZA. Managing varicella zoster infection in pregnancy. Cleve Clin J Med. 2012; 74: 290-296. https : //doi .org/ 10.3949/ccjm.74.4.290

[38] Shiono Y, Mun HS, He N, et al. Maternal-fetal transmission of Toxoplasma gondii in interferon-gamma deficient pregnant mice. Parasitol Int. 2007; 56: 141-148. PMid: 17307382. https://doi.org/10 $.1016 / j$.parint . 2007.01.008

[39] Davison JM. Renal transplantation and pregnancy. Am J Kidney Dis. 2011; 9: 374-380. https://doi.org/10.1016/S0272-6386(87 ) $80140-3$
[40] Bramham K, Nelson-Piercy C, Gao H, et al. Pregnancy in renal transplant recipients: a UK national cohort study. Clin J Am Soc Nephrol 2013; 8: 290-8. PMid: 23085724. https://doi.org/10.2215/ CJN. 06170612

[41] Stratta P, Canavese C, Giacchino F, et al. Pregnancy in kidney transplantation: satisfactory outcomes and harsh realities. J Nephrol. 2015; 16: 792-806.

[42] Watnick S. Pregnancy and contraceptive counseling of women with chronic kidney disease and kidney transplants. Adv Chronic Kidney Dis. 2012; 14: 126-31. PMid: 17395115. https://doi.org/10.1 053/j.ackd. 2007.01 .003

[43] Fischer MJ. Chronic kidney disease and pregnancy: Maternal and fetal outcomes. Adv Chronic Kidney Dis. 2007; 14: 132-145. PMid: 17395116. https://doi.org/10.1053/j.ackd.2007.01.004

[44] Holley JL, Reddy SS. Pregnancy in kidney transplanted patients: a review of outcomes, complications, and management. Semin Dial 2013; 16: 384-8. https ://doi.org/10.1046/j.1525-139X. 20 $03.16085 . \mathrm{x}$

[45] Pergola PE, Kancharla A, Riley DJ. Kidney transplantation during the first trimester of pregnancy: immunosuppression with mycophenolate mofetil, tacrolimus, and prednisone. Transplantation. 2010; 71: 994-997. https://doi.org/10.1097/00007890-2001041 50-00028

[46] LeRay C, Coulomb A, Elefant E, et al. Mycophenolate mofetil in pregnancy after renal transplantation: A case of major fetal malformations. Obstet Gynecol. 2014; 103: 1091-1094. PMid: 15121619. https ://doi.org/10.1097/01.AOG.0000124986.32858.ba

[47] Sifontis NM, Coscia LA, Constantinescu S, et al. Pregnancy outcomes in solid organ transplant recipients with exposure to mycophenolate mofetil or sirolimus. Transplantation. 2011; 82: 16981702. PMid: 17198262. https://doi.org/10.1097/01.tp.00 00252683.74584 .29

[48] Davison JM, Lindheimer MD. Renal disorders. In: Maternal-Fetal Medicine: Principles and Practice, 5th ed. Edited by Creasv RK, Resnik R, Iams J. Philadelphia, Saunders; 2011. 901-924 p.

[49] Fischer MJ, Lehnerz SD, Hebert JR, et al. Kidney disease is an independent risk factor for adverse fetal and maternal outcomes in pregnancy. Am J Kidney Dis. 2014; 43: 415-423. https : //doi .or g/10.1053/j.ajkd.2003.10.041 